\title{
Prevalence of Malnutrition Among Iran's Under Five-Year-Old Children and the Related Factors: A Systematic Review and
}

\author{
Meta-Analysis \\ Mohammad Mohseni, ${ }^{1}$ Aidin Aryankhesal, ${ }^{1,2, *}$ and Naser Kalantari ${ }^{3}$ \\ ${ }^{1}$ School of Health Management and Information Sciences, Iran University of Medical Sciences, Tehran, Iran \\ ${ }^{2}$ Health Management and Economics Research Center, Iran University of Medical Sciences, Tehran, Iran \\ ${ }^{3}$ Faculty of Nutrition and Food Technology, Shahid Beheshti University of Medical Sciences, Tehran, Iran \\ "Corresponding author: Dr. Aidin Aryankhesal, Health Management and Economics Research Center, Iran University of Medical Sciences, Tehran, Iran. E-mail: \\ aryankhesal.a@iums.ac.ir
}

Received 2016 September 29; Revised 2017 February 22; Accepted 2017 December 16.

\begin{abstract}
Context: Children's health is one of the priorities in most societies. Nevertheless, the highest prevalence rate of malnutrition occurs among under five-year-old children worldwide.

Objectives: The aim of this study was to estimate the rate of malnutrition in Iranian children through a systematic review and meta-analysis. Also we tried to identify the most prevalent factors causing malnutrition.

Data Sources: The required data were collected by searching the keywords of nutrition, malnutrition, under-nutrition, prevalence, epidemiology, etiology, occurrence and Iran in PubMed, Google Scholar, Scopus, Index Copernicus, DOAJ, EBSCO-CINAHL, SID, Magiran and Iranmedex.

Results: Twenty studies were selected for the final analysis stage, dating from 1999 to 2014 . Number of children investigated for wasting, stunting and underweight was 53612, 54312 and 55012 respectively. The results showed that the prevalence of each type of malnutrition, in terms of wasting, stunting and underweight were 7.8\% (95\% CI: 4.8\% - 12.6\%), 12.4\% (95\% CI: 8.3\% - 18.5\%) and 10.5\% (95\% CI: 7.1\% -15.4\%), respectively. Parents' educational level, in particular mothers', gender, birth weight, the place of residence, and mother's occupation were mentioned as important factors causing malnutrition.

Conclusion: The rate of malnutrition in Iran's under five-year-old children is lower than the average of that in world and the Eastern Mediterranean region. Breastfeeding, the proper use of complementary feeding, and the principled spacing between births and improving the quality of maternal care have important role in prevention of malnutrition.
\end{abstract}

Keywords: Malnutrition, Stunting, Underweight, Wasting, Children, Meta-Analysis

\section{Context}

Children constitute a significant percentage of the world population and the provision and promotion of their health are among the first health priorities in societies. Due to special dietary needs for their growth, children are significantly at risk of malnutrition (1). Malnutrition is a state in which a deficiency, excess or imbalance of energy, protein and other nutrients causes adverse effects on body form or performance and clinical outcomes (2). Malnutrition affects all population groups, but is more common in infants and children due to their rapid linear growth (3). Hence, reducing malnutrition has been considered across two of the millennium development goals (MDGs) by the world health organization (WHO); the first was related to eradication of extreme poverty and hunger and the other was related to reduction of child mortality

\section{$(4,5)$.}

The first effect of malnutrition is on growth, including weight loss, arm circumference reduction, delays in completion of bone growth, reduction in weight to height ratio and reduction in natural skin-folds (6). In addition, in the first years of life, malnutrition is a cause of slow body growth, short stature and reduction of intellectual development of children that leads to recurrent and treatmentresistant infections (7). Marasmus and Kwashiorkor, as examples, both forms of severe malnutrition, end with high rates of mortality $(8,9)$.

To calculate the anthropometric index in order to determine malnutrition status in children, height, weight and age are traditionally used (6). Stunting (low height for age), wasting (low weight for height) and underweight (low weight for age) are main indicators which can be cal- 
culated using these items. Stunting associated with malnutrition in children represents chronic malnutrition or a long-term illness, while wasting is an indication of severe acute malnutrition that a disease or inadequate intake of food can cause. Underweight also reflects a combination of acute and chronic malnutrition (10). According to the UNICEF annual report 2014 regarding these indicators, the prevalence of underweight, stunting, wasting and moderate and severe overweight in the world have been 15, 25, 8 and 7 percent respectively (11). Statistics show that the highest prevalence of malnutrition exists in infants and pre-school children, and malnutrition plays a significant role in the mortality of children under 5 years old. About 45 percent of child mortality was estimated to be attributable to malnutrition in 2011 (12). Also, global estimates showed that there were 51 million wasted, 162 million stunted and 99 million underweight children in the world (13). The result of other studies in developing nations also showed that despite socio-economic developments, malnutrition in children still exists as a significant health issue $(14,15)$.

In Iran, results of a study on a sample of 34200 children across 28 provinces of the country showed that 4.7 , 2.5 and 3.7 percent of children suffered from stunting, underweight and wasting in 2008, respectively (16). Although recent studies indicate tangible reduction in the percentage of children suffering from malnutrition, this issue in some areas is still considered as a major health problem (17). Nevertheless, there is no recent and precise estimation of malnutrition across Iranian children. The aim of this study was to develop such estimate through a systematic review and meta-analysis and review the causes of malnutrition in Iran's under five-year-old children.

\section{Methods}

We conducted a systematic review and meta-analysis in 2015 according to the preferred reporting items for systematic reviews and meta-analyses (PRISMA) statement $(18,19)$.

\subsection{Search Strategy}

The search was conducted on October 2015 and no restriction was placed on studies' publication date. We searched PubMed, Google Scholar, Scopus, Index Copernicus, DOAJ, EBSCO-CINAHL, Iranmedex, SID, and Magiran. The electronic search strategy included the following keywords: nutrition, malnutrition, child malnutrition, undernutrition, prevalence, epidemiology, etiology, occurrence and Iran. The electronic searches were independently conducted by two authors (MM, and AA), plus hand-searching of relevant journals and looking at references lists of the retrieved papers. A reference management software (Endnote X5) was used to export and manage the retrieved documents.

\subsection{Study Selection}

Two reviewers (MM and AA) independently screened the titles and abstracts to find potentially eligible studies for the full text review. The kappa coefficient which shows the agreement rate between two reviewers on the included papers was 0.801 . In cases that two reviewers disagreed, the third author was consulted. The inclusion criteria were the originality of research (primary data), and reporting prevalence of malnutrition (of any indicators of stunt, waste or underweight), among under 5 years population based on NCHS/WHO standard. The exclusion criterion was publication languages other than English or Persian. The primarily included studies' quality was examined by 'strengthening the reporting of observational studies in epidemiology' (STROBE) checklist (20).

\subsection{Data Extraction}

Using a data collection form, with same column titles included in Table 1, data were extracted from the included articles. The following information was extracted for each study.

\subsection{Data Analysis}

Computer software CMA:2 (Comprehensive MetaAnalysis) was applied for meta-analysis. The Cochrane Q statistic was calculated to assess the heterogeneity of data. The random effects model was used with 95\% confidence interval to estimate the malnutrition prevalence. Publication bias was investigated using funnel plots. Microsoft Office Excel 2010 was used for drawing the graphs.

\section{Results}

Twenty articles out of 527 primarily retrieved studies were entered for the final analysis (see Table 1). The articles were published between 1999 and 2014, of which 17 studies reported about wasting, 18 reported stunting and 19 of the included studies reported underweight rates. The pooled samples for each of wasting, stunting and underweight were 53612, 54312 and 55012 respectively. The results showed that the prevalence of each type of malnutrition, in terms of wasting, stunting and underweight were 7.8 (95\% CI: 4.8\% - 12.6\%), 12.4\% (95\% CI: 8.3\% - 18.5\%) and 10.5\% (95\% CI: $7.1 \%$ - 15.4\%) respectively. Parents' educational level, in particular mothers' educational level, place of residence, gender, employment status of mother, birth 


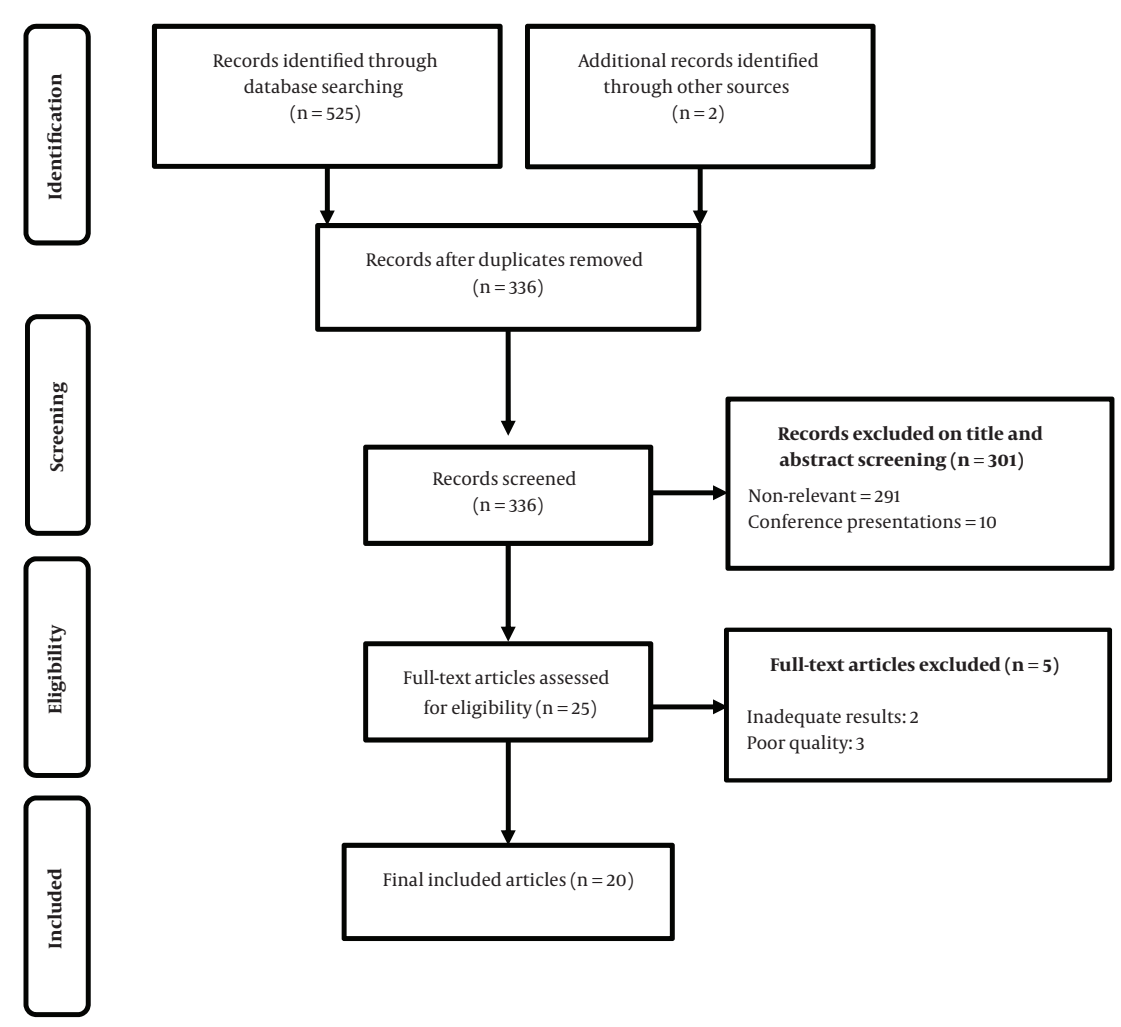

Figure 1. Flow Diagram for Study Selection

weight of less than 2500 grams, birth order, medical history, household socioeconomic status and family size were mentioned as important factors resulting in malnutrition.

The prevalence of malnutrition for all studies based on the random effects model was calculated. The overall prevalence of wasting was determined to be $7.8 \%$ (95\% CI: 4.8 - 12.6), $\mathrm{Q}=238.8, \mathrm{df}=16, \mathrm{P}<0.001, \mathrm{I}^{2}=93.30$ (Figure 2 ). The overall prevalence of stunting in under 5 year old children in Iran based on the random effect model was determined to be $12.4 \%$ (95\% CI: $8.3-18.5$ ), $\mathrm{Q}=276.9$, $\mathrm{df}=17, \mathrm{P}<$ $0.001, \mathrm{I}^{2}=93.86$ (Figure 3 ). The overall prevalence of underweight was determined to be 10.5\% (95\% CI: 7.1 - 15.4), Q = 227.50, df =18, $\mathrm{P}<0$. 001, $\mathrm{I}^{2}=92.08$ (Figure 4). The probability of publication bias was investigated just for stunting data (Figure 5), where there are some signs of bias.

According to Table 1 parents' educational level, in particular mothers' educational level can play a significant role. The results of the assessment at the country level in Iran also indicate a declining trend of the nutritional underweight prevalence in children under five years of age in recent years. This rate decreased from 15.5 to 4.7 percent between 1995 and 2004 (21). Also place of residence (urban or rural areas), gender of child, employment status of mother, and birth weight were mentioned as factors affecting malnutrition.

\section{Discussion}

The results showed that the prevalence of each type of malnutrition, in terms of wasting, stunting and underweight were $7.8,12.4$ and 10.5 percent, respectively. One reason for the rather high overall prevalence of all three indicators in this review is that the majority of studies were conducted in the cities or provinces in which socioeconomic status was middle or low and we know that health and economic differences across Iranian provinces are very wide $(22,23)$. The household socioeconomic status has been reported as one of the main factors of children malnutrition. Generally, it seems that there is more willing to study the prevalence in areas where prevalence of the desired factor or disease is higher. However, the overall prevalence of each of three indicators is in a good status compared to global statistics; UNICEF's annual report in 2014 showed that the prevalence of wasting, stunting and underweight in the world were 8, 25 and 15 percent, respectively (11). The global statistics about wasting in 2014 show 


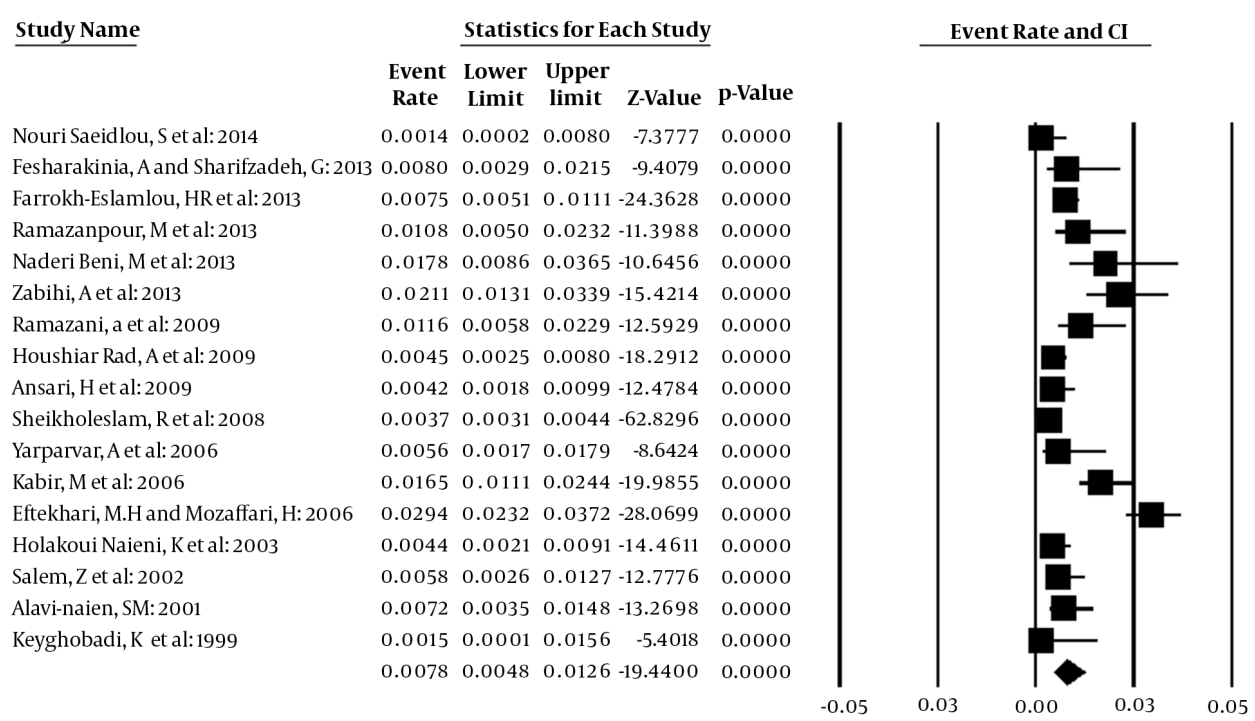

Figure 2. The Overall Prevalence of Wasting in Under 5 Years Old Children in Iran

Study Name

Nouri Saeidlou, S et al: 2014 Fesharakinia, A and Sharifzadeh, G: 2013 Farrokh-Eslamlou, HR et al: 2013

Ramazanpour, M et al: 2013

Naderi Beni, M et al:2013

Zabihi, A et al:2013

Mohammadinia, $\mathrm{N}$ et al: 2012

Ramazani, a et al: 2009

Houshiar Rad, A et al: 2009

Ansari, $\mathrm{H}$ et al: 2009

Sheikholeslam, Retal: 2008

Yarparvar, A et al: 2006

Kabir, M et al: 2006

Eftekhari, M.H and Mozaffari, H: 2006

Holakoui Naieni, Ket al: 2003

Salem, Z et al: 2002

Alavi-naien, SM: 2001

Keyghobadi, K et al:1999

\section{Statistics for Each Study}

Event Lower Upper

Rate Limit limit z-Value p-Value

$\begin{array}{llllll}0.0073 & 0.0034 & 0.0156 & -12.5598 & 0.0000\end{array}$

$\begin{array}{lllllll}0.0098 & 0.0040 & 0.0240 & -9.9613 & 0.0000\end{array}$

$\begin{array}{lllllll}0.0087 & 0.0061 & 0.0125 & -25.4205 & 0.0000\end{array}$

$\begin{array}{llllll}0.0093 & 0.0041 & 0.0212 & -10.9397 & 0.0000\end{array}$

$\begin{array}{llllll}0.0370 & 0.0224 & 0.0605 & -12.3501 & 0.0000\end{array}$

$\begin{array}{llllll}0.0083 & 0.0039 & 0.0178 & -12.1352 & 0.0000\end{array}$

$\begin{array}{llllll}0.0111 & 0.0055 & 0.0223 & -12.4451 & 0.0000\end{array}$

$\begin{array}{llllllll}0.0053 & 0.0019 & 0.0146 & -10.0561 & 0.0000\end{array}$

$\begin{array}{llllll}0.0130 & 0.0093 & 0.0182 & -24.8245 & 0.0000\end{array}$

$\begin{array}{llllll}0.0076 & 0.0040 & 0.0143 & -14.9293 & 0.0000\end{array}$

$\begin{array}{llllll}0.0047 & 0.0040 & 0.0055 & -67.7388 & 0.0000\end{array}$

$\begin{array}{llllll}0.0089 & 0.0035 & 0.0223 & -9.8972 & 0.0000\end{array}$

$\begin{array}{llllll}0.0314 & 0.0236 & 0.0416 & -22.9515 & 0.0000\end{array}$

$\begin{array}{llllll}0.0268 & 0.0209 & 0.0343 & -27.5670 & 0.0000\end{array}$

$\begin{array}{llllll}0.0244 & 0.0179 & 0.0331 & -22.9335 & 0.0000\end{array}$

$0.0103 \quad 0.00570 .0185-15.0774 \quad 0.0000$

$\begin{array}{llllll}0.0153 & 0.0093 & 0.0250 & -16.2852 & 0.0000\end{array}$

$\begin{array}{lllll}0.0194 & 0.0101 & 0.0369 & -11.6173 & 0.0000\end{array}$

$\begin{array}{lllll}0.0124 & 0.0083 & 0.0185 & -21.1180 & 0.0000\end{array}$

\section{Event Rate and CI}

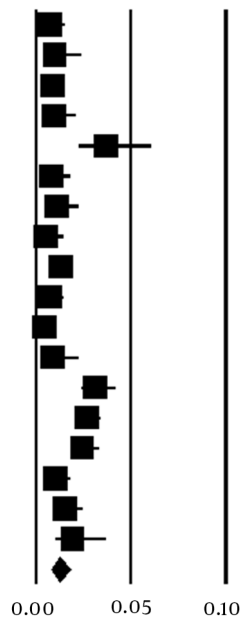

Figure 3. The Overall Prevalence of Stunting in Under 5 Years Old Children in Iran

that almost one out of every 13 children in the world suffer from wasting and one third of all children suffer from severe wasting (16 out of the 50 million with a global prevalence of $4.2 \%$ ) (13). Of course, low wasting prevalence in a society does not mean the absence of malnutrition (24). The global statistics about stunting show that the number of stunted children decreased from 255 million to 159 million children between 1990 and 2014 (13).

According to the 2014 World Bank report, Iran was ranked among countries with low prevalence stunting (4 percent). The indicator across Middle East and North Africa was 32 percent and 48 in South Asia (25). Also, results of a study conducted in Nairobi on 5156 children under 42 months old showed that $40 \%$ of children suffered from stunting (26). Results of a study conducted in Indonesia on children under five showed that $38.4 \%$ and $18.4 \%$ of children suffered from stunting and severe stunting, respectively. In Bangladesh, the prevalence of underweight, 


Study Name
Nouri Saeidlou, S et al: 2014
Fesharakinia, A and Sharifzadeh, G: 20130.
Farrokh-Eslamlou, HR et al: 2013
Ramazanpour, M et al: 2013
Naderi Beni, M et al: 2013
Zabihi, A et al:2013
Mohammadinia, N et al: 2012
Ramazani, a et al: 2009
Houshiar Rad, A et al: 2009
Ansari, H et al: 2009
Sheikholeslam, R et al: 2008
Yarparvar, A et al: 2006
Kabir, M et al: 2006
Eftekhari, M.H and Mozaffari, H: 2006
Holakoui Naieni, K et al: 2003
Nakhshab, M et al: 2002
Salem, Z et al: 2002
Alavi-naien, SM: 2001
Keyghobadi, K et al: 1999

$\begin{array}{lll}\text { Event } & \text { Lower Upper } \\ \text { Rate Limit limit Z-Value p-Value }\end{array}$

$\begin{array}{lllll}0.0023 & 0.0006 & 0.0089 & -8.7365 & 0.0000\end{array}$

$\begin{array}{llllll}0.0063 & 0.0020 & 0.0193 & -8.7729 & 0.0000\end{array}$

$\begin{array}{llllll}0.0043 & 0.0026 & 0.0072 & -20.5931 & 0.0000\end{array}$

$\begin{array}{llllll}0.0105 & 0.0048 & 0.0228 & -11.3120 & 0.0000\end{array}$

$\begin{array}{llllll}0.0345 & 0.0205 & 0.0575 & -12.2068 & 0.0000\end{array}$

$\begin{array}{llllll}0.0147 & 0.0083 & 0.0260 & -14.1522 & 0.0000\end{array}$

$\begin{array}{llllll}0.0098 & 0.0046 & 0.0206 & -12.0294 & 0.0000\end{array}$

$\begin{array}{llllll}0.0106 & 0.0052 & 0.0216 & -12.2909 & 0.0000\end{array}$

$\begin{array}{lllllll}0.0076 & 0.0049 & 0.0118 & -21.4163 & 0.0000\end{array}$

$\begin{array}{llllll}0.0034 & 0.0013 & 0.0088 & -11.6675 & 0.0000\end{array}$

$\begin{array}{llllll}0.0052 & 0.0045 & 0.0060 & -69.8816 & 0.0000\end{array}$

$\begin{array}{lllll}0.0152 & 0.0075 & 0.0306 & -11.4113 & 0.0000\end{array}$

$\begin{array}{llllll}0.0214 & 0.0151 & 0.0302 & -212317 & 0.0000\end{array}$

$\begin{array}{llllll}0.0292 & 0.0230 & 0.0370 & -28.0334 & 0.0000\end{array}$

$\begin{array}{llllll}0.0054 & 0.0028 & 0.0104 & -15.4045 & 0.0000\end{array}$

$\begin{array}{llllll}0.0137 & 0.0073 & 0.0256 & -13.1525 & 0.0000\end{array}$

$\begin{array}{llllll}0.0115 & 0.0066 & 0.0200 & -15 & 5333 & 0.0000\end{array}$

$\begin{array}{llllll}0.0161 & 0.0099 & 0.0260 & -16.4911 & 0.0000\end{array}$

$\begin{array}{llllll}0.0162 & 0.0079 & 0.0328 & -11.1307 & 0.0000\end{array}$

$\begin{array}{llllll}0.0105 & 0.0071 & 0.0154 & -22.8716 & 0.0000\end{array}$

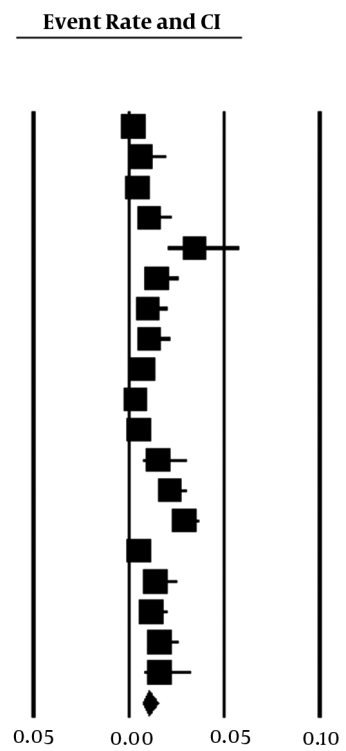

Figure 4. The Overall Prevalence of Underweight in Under 5 Years Old Children in Iran

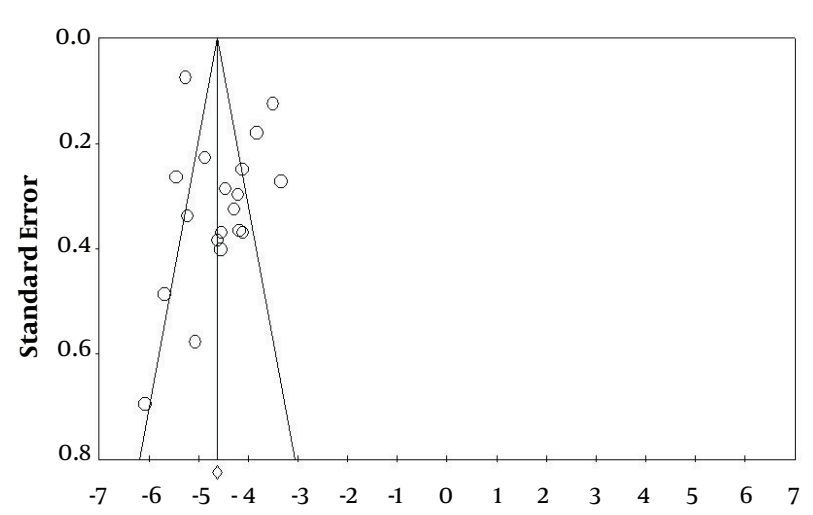

Figure 5. The Funnel Plot of Standard Error Across Published Papers on Stunting

stunting and wasting in children under five were 41,43 and 17 percent respectively (27). Cultural and economic status can be mentioned as factors contributing to stunting. Also, underweight reflects a combination of acute and chronic malnutrition (10). This means that short-term factors gradually provide ground for underweight and if the improper nutritional status or disease continues for any reason, it can in suffering children lead to wasting.

Parents', in particular mothers' educational level, place of residence, gender of child, employment status of mother, and birth weight were mentioned as factors affecting malnutrition. In line with the findings of the current study, in the study conducted in Nairobi there was a sig- nificant correlation between stunting and the masculine gender of child, mother educational level and birth weight (26). Low birth weight was also reported as one important reason for underweight in children in Bangladesh, its main cause being intrauterine growth restriction (27). Furthermore, among children under five in Indonesia, there was a significant correlation between stunting and the household income level, the employment status of father, the masculine gender of child and age of child (28). Mothers' educational level can play a significant role in the incidence or absence of malnutrition in children. Lack of mothers' awareness of how to use complementary foods properly, the way of preparing them and how to start complementary feeding can result in underweight and wasting in the children after 6 months of age (29). Also, lack of mothers' awareness of children's nutritional needs while breastfeeding withdrawal and financial ability to prepare complementary food are important factors affecting adequacy and appropriateness of children's diet in accordance with their nutritional needs (30).

The results of studies conducted in Iran also showed that the age for starting complementary feeding can be considered as a factors of the incidence of malnutrition and children may suffer from nutrient shortages when switching from breastfeeding to complementary food. So it can be said that the most common starting point of malnutrition and growth retardation in children can occur from the age of 6 months onward. In this regard, parents' educational needs should be met through implementing 
educational programs. Also the economic status of households with children in the growth stage should be responsive to basic nutritional needs of children.

Our review had some limitations. As mentioned earlier, the selected studies were generally conducted in rather deprived regions of the country and not all provinces were included in the final pooling of the malnutrition indicators. Only two studies were conducted nationwide. Hence we expect that the pooled data in the meta-analysis are overestimated. Moreover, the included data ranged 1999 to 2014. Pooling such longitudinal data can cause regression to mean, blurring any possible improvement in the studied indicators. Another cause of concern was about the heterogeneity of the pooled data. As the findings show the heterogeneity of pooled data was statistically significant $(\mathrm{P}=0.001)$ and severe $\left(\mathrm{I}^{2}=90\right)$ in all malnutrition indicators.

\section{Conclusion}

Effective solutions exist for reducing malnutrition in children. Increasing health literacy and promoting the culture of proper nutrition, equitable distribution of health care and services, solving economic obstacles, regular monthly weighting and growth monitoring for children, emphasizing on the importance of breastfeeding and the proper use of complementary feeding and finally the principled spacing between births and improving the quality of maternal care are matters of great importance for the prevention of malnutrition. The findings of this review reflect the importance of nutrition in under-five-year children and proper policy making in this area.

\section{Acknowledgments}

This study was part of a PhD thesis supported by Iran University of Medical Sciences (grant No: IUMS/SHMIS 1394/9221557201).

\section{References}

1. Moridi G, Fathi M. Malnutrition in children under five in Iran [In Persian].J Nurs Midwifery. 2009;19(64).

2. Stratton RJ, Green CJ, Elia M. Disease-related malnutrition: an evidencebased approach to treatment. Cabi; 2003.

3. Ramazanpour M, Akaberi A, Khoshnoud Ostad E, Shoraka H. Investigation into malnutrition Prevalence rate and effective factors on under-five-year-old children in Maneh-Semelghan city (2012-2013) [In Persian]. J North Khorasan Uni Med Sci. 2013;5(4):374.

4. WHO.MDG 1: eradicate extreme poverty and hunger 2014. 2014. Available from: http://www.who.int/topics/millennium_development_goals/ hunger/en/.

5. WHO . Global health observatory (GHO) data 2015. 2015. Available from http://www.who.int/gho/child_health/mortality/mortality_under_ five_text/en/.
6. Kashfi S, Khani Jeihooni A. The prevalence of protein-energy malnutrition (pem) in children under 5 years in Abadeh city [In Persian].J Fasa Uni Med Sci. 2014;3(4):363-70.

7. Kliegman RM, Stanton B, Geme JS, Schor NF, Behrman RE. Nelson Textbook of Pediatrics. Elsevier Health Sciences; 2015.

8. Briend A. Kwashiorkor: still an enigma-the search must go on. CMAM Forum Technical Brief; 2014.

9. Talbert A, Thuo N, Karisa J, Chesaro C, Ohuma E, Ignas J, et al. Diarrhoea complicating severe acute malnutrition in Kenyan children: a prospective descriptive study of risk factors and outcome. PLoS One. 2012;7(6). e38321. doi: 10.1371/journal.pone.0038321. [PubMed: 22675542].

10. World Health Organization . hysical status: The use of and interpretation of anthropometry, Report of a WHO Expert Committee. World Health Organization; 1995.

11. UNICEF. The State Of The World's Children 2014. 2014.

12. Black RE, Victora CG, Walker SP, Bhutta ZA, Christian P, de Onis M, et al. Maternal and child undernutrition and overweight in lowincome and middle-income countries. Lancet. 2013;382(9890):427-51. doi:10.1016/S0140-6736(13)60937-X. [PubMed: 23746772].

13. UNICEF, WHO . World Bank Group. Levels and trends in child malnutrition. 2015.

14. Masibo PK, Makoka D. Trends and determinants of undernutrition among young Kenyan children: Kenya Demographic and Health Survey;1993,1998, 2003 and 2008-2009. Public Health Nutr. 2012;15(9):171527. doi: 10.1017/S1368980012002856. [PubMed: 22694984].

15. Demissie S. Magnitude and factors associated with malnutrition in children 6-59 months of age in pastoral community of Dollo Ado district, Somali Region, Ethiopia. Sci J Pub Health. 2013;1(4):175-83. doi: 10.11648/j.sjph.20130104.12.

16. Sheikholeslam R, Naghavi M, Abdollahi Z. Current status and the 10 years trend in the malnutrition indexes of children under 5 years in Iran [In Persian]. Iran J Epidemiol. 2008;4(1):21-8.

17. Emamian MH, Gorgani N, Fateh M. Malnutrition status in children of Shahroud, Iran. Knowl Health. 2011;6(11):7-14.

18. Moher D. Preferred reporting items for systematic reviews and metaanalyses: The PRISMA statement. Ann Intern Med. 2009;151(4):264-9. doi: 10.7326/0003-4819-151-4-200908180-00135.

19. Liberati A. The PRISMA statement for reporting systematic reviews and meta-analyses of studies that evaluate health care interventions: Explanation and elaboration. Ann Inter Med. 2009;151(4):65-94. doi: 10.7326/0003-4819-151-4-200908180-00136.

20. Vandenbroucke JP, Von Elm E, Altman DG. Strengthening the reporting of observational studies in epidemiology (STROBE): explanation and elaboration. Ann inter Med. 2007;147(8):163-94.

21. Farrokh-Eslamlou HR, Oshnouei S, Ahmadi N, Babaei F. Geographical distribution of nutrition deficiency among children under five years old in the West Azerbaijan Province, Iran [In Perian]. Urmia Med J. 2013;24(3):201-9.

22. Sabermahani A, Barouni M, Seyedin H, Aryankhesal A. Provincial human development index, a guide for efficiency level analysis: the case of iran. Iran J Public Health. 2013;42(2):149-57. [PubMed: 23515434].

23. Abolhallaje M, Mousavi SM, Anjomshoa M, Beigi Nasiri A, Seyedin H, Sadeghifar J, et al. Assessing health inequalities in Iran: a focus on the distribution of health care facilities. Glob JHealth Sci. 2014;6(4):285-91. doi: 10.5539/gjhs.v6n4p285. [PubMed: 24999132].

24. O'Donnell OA, Wagstaff A. Analyzing health equity using household survey data: a guide to techniques and their implementation. World Bank Publications; 2008.

25. Fotso JC. Urban-rural differentials in child malnutrition: trends and socioeconomic correlates in sub-Saharan Africa. Health Place. 2007;13(1):205-23. doi: 10.1016/j.healthplace.2006.01.004. [PubMed: 16563851]. 
26. Abuya BA, Ciera J, Kimani-Murage E. Effect of mother's education on child's nutritional status in the slums of Nairobi. BMC Pediatr. 2012;12:80. doi: 10.1186/1471-2431-12-80. [PubMed: 22721431].

27. Ahmed T, Mahfuz M, Ireen S, Ahmed AM, Rahman S, Islam MM, et al. Nutrition of children and women in Bangladesh: trends and directions for the future. J Health Popul Nutr. 2012;30(1):1-11. doi 10.3329/jhpn.v30i1.11268. [PubMed: 22524113].

28. Agho KE, Inder KJ, Bowe SJ, Jacobs J, Dibley MJ.Ramli. Prevalence and risk factors for stunting and severe stunting among under-fives in North Maluku province of Indonesia. BMC Pediatr. 2009;9:64. doi 10.1186/1471-2431-9-64. [PubMed: 19818167].

29. Naderi Beni M, Lak R, Jazaeri S, Eftekhar Ardebili H. Prevalence of malnutrition under five years in Chadegan (area district city) Iran 2011 [In Persian]. Iran J Epidemiol. 2013;9(2):22-8.

30. Parsay S, Soltani R. Maternal and Child Health. 5 ed. Tehran: Sanjesh Press; 2012.

31. Keyghobadi K, Jazayeri A, Keshavarz A. Nutritional status of 2-5 yearold children and the effect of some known factors in the rural areas of Khoramabad.J Kerman Uni Med Sci.1999;6(2):82-8.

32. Alavi Naeini M. The study of the prevalence of malnutrition and its related factors among zero to 59 month old children in Birgand rural areas. J Tehran Faculty Med. 2001;1(59):99-103.

33. Nakhshab M, Nasiri H. A study on the prevalence rate of malnutrition and it's effective factors in children under two years in Sari township 1999-2000 [In Persian]. J Mazandaran Uni Med Sci. 2002;12(34):47-56.

34. Salem Z, Sheikhfatolahi M, Esmaeili A. Prevalence of malnutrition in children 1-5 years old in Rafsanjan city in the year 2000 [In Persian]. Rafsanjan Uni Med Sci. 2002;1(14):260-6.

35. Holakoui Naieni K, Sadeghipour Rodsary H, Panahandeh Z. Monitoring growth in children aged up to 5 years In Islamshahr, Rey and Qom [In Persian]. J Sch Pub Health Inst Pub Health Res. 2003;1(1):17-27.

36. Yarparvar A, Omidvar N, Golestan B, Kalantari N. Assessing the nutri- tional status of the preschool 6-59 month old children and some related factors in earthquake affected areas of Bam [In Persian]. Nutr Sci Food Technol. 2006;1(1):33-43.

37. Kabir M, Keshtkar A, Lashkar Bolouki F. Prevalence of malnutrition in children under 2 years old and its relationship with mothers background variables in Golestan province [In Persian]. Gorgan Uni Med Sci J. 2006;8(32-9).

38. Eftekhari M, Mozaffari H. The prevalence of malnutrition in children under 5 years in Lar and its outskirts [In Persian]. Toloo e Behdasht. 2006;5(1-2):13-23.

39. Ramazani A, Raghebi S, Amirkhizi F. The survey of the nutritional status and related factors in 0-24 month-old children in South Khorasan Province in Iran 2006 [In Persian]. Iran J Epidemiol. 2009;5(4):8-13.

40. Houshiar Rad A, Dorosty A, Kalantari N. Prevalence of stunting, underweight, wasting and overweight among Iranian under-five-yearold children (2000-2002). Iran J Nutr Sci Food Technol. 2009;3(4):49-56.

41. Ansari H, Zareban I, Norouzi M. Predictors of malnutrition among Zahedan ; rsquo; s children age ranging from 2-5 years old in 2007-2008. J Shahrekord Uni Med Sci. 2009;11(3):46-54.

42. Mohammadinia N, Sharifi H, Rezaei MA, Heydari N. The Prevalence of Malnutrition among Children under 5 Years old Referred to Health Centers in Iranshahr during 2010-2011. J Occup Health Epidemiol. 2012;1(3):139-49. doi: 10.18869/acadpub.johe.1.3.139.

43. Fesharakinia A, Sharifzadeh G. Prevalence of malnutrition in under 5year old children in Birjand city in 2011 [In Persian]. J Birjand Uni Med Sci. 2013;20(1):77-84.

44. Zabihi A, Rafati Rahimzadeh M, Jafarian Amiri S. Effect of growth indices on malnutrition in infants from health medical centers of Babol, Iran 2011-2012 [In Persian]. J Babol Uni Med Sci. 2013;15(6):59-65.

45. Nouri Saeidlou S, Babaei F, Ayremlou P. Prevalence of malnutrition in children under 5 years old in Salmas, and comparing to Ravansar and Samirom [In Persian]. Razi J Med Sci. 2014;21(124):47-53. 
Table 1. Summary of the Included Papers

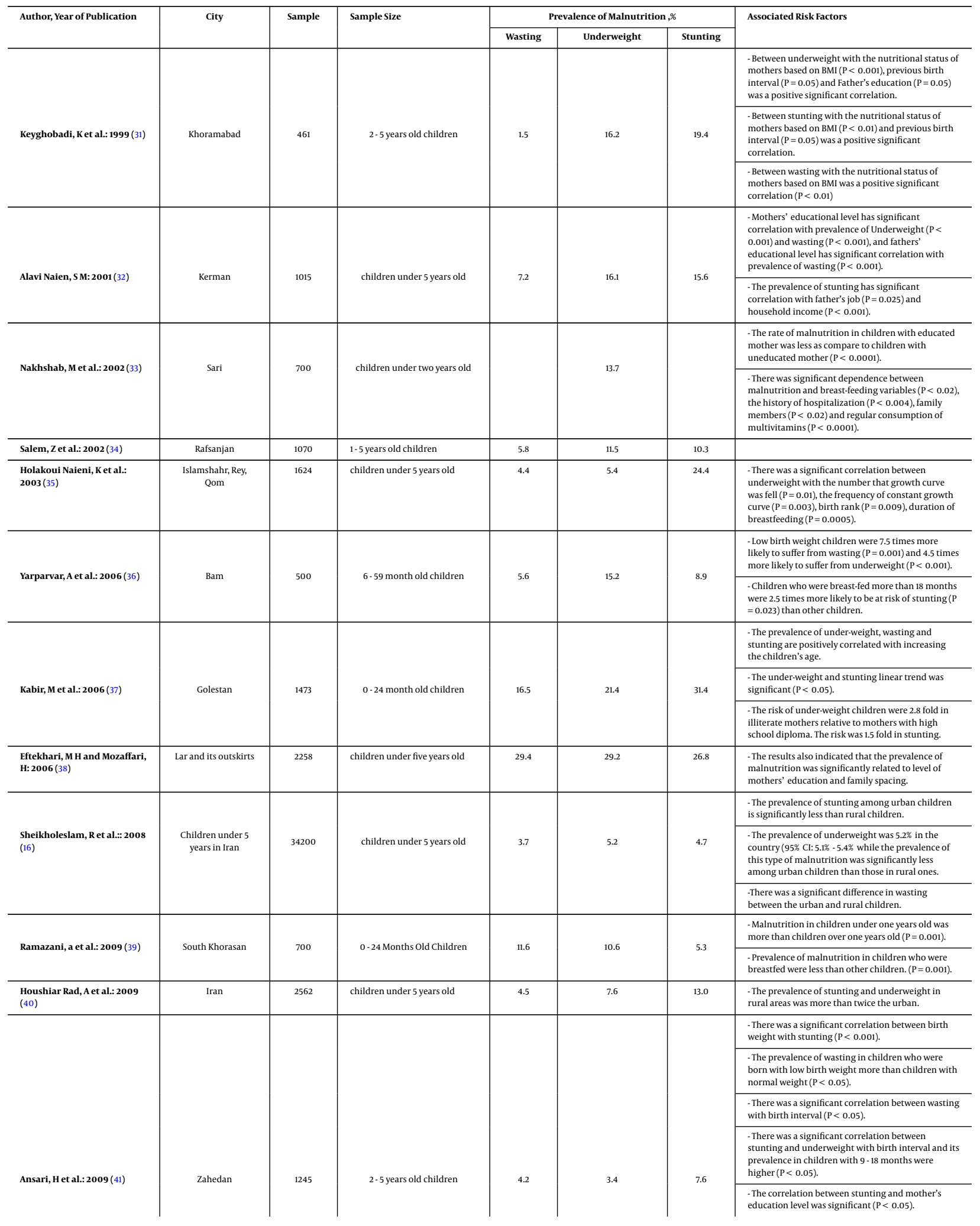




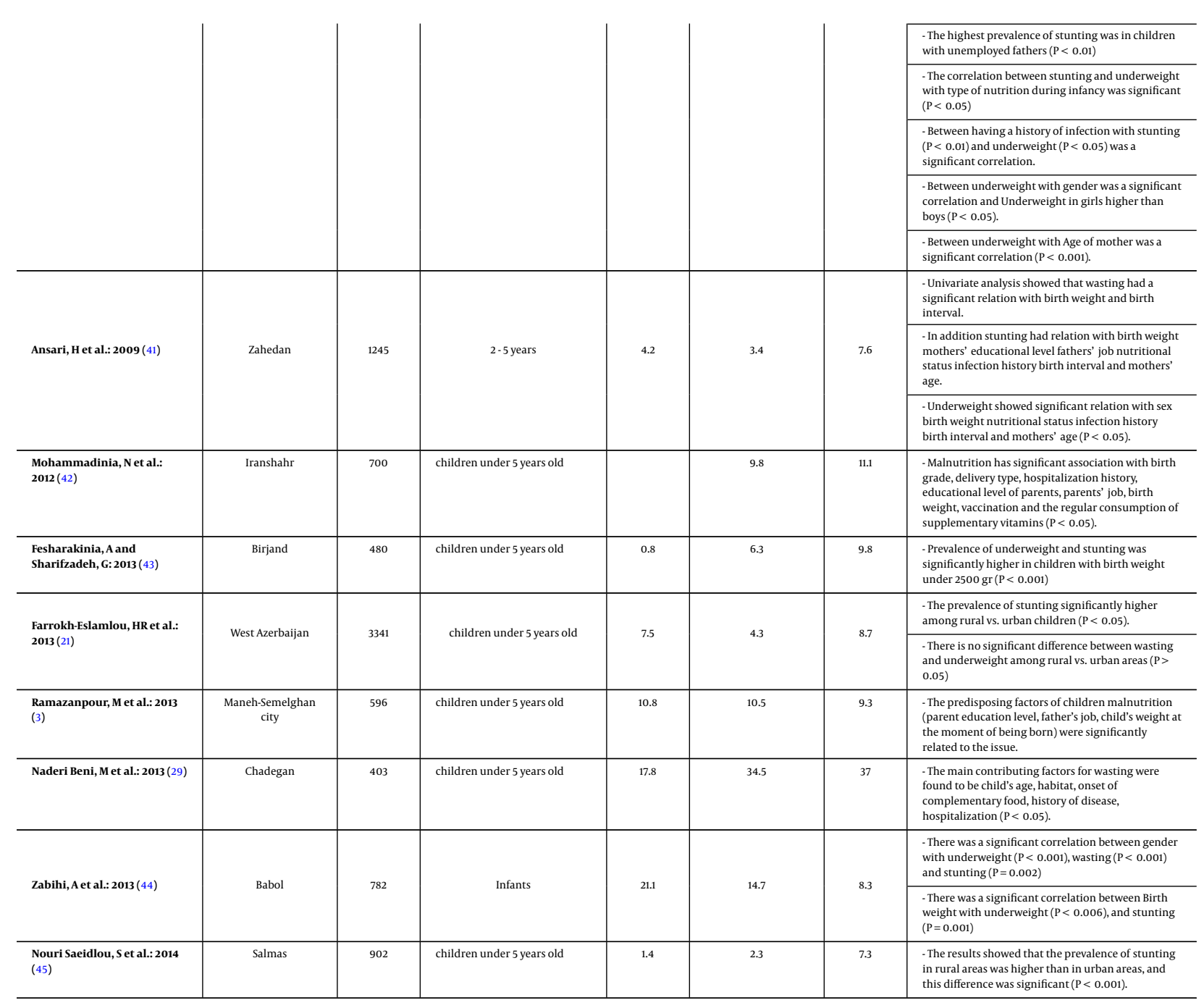

